INTRODUCTION. THEORETICAL FOUNDATION OF THE DEVELOPED MULTIFACTORIAL MODEL OF ATTITUDES TOWARDS AP

This investigation is focusing the interrelations of attitudes towards appearance (AP), values, functional significance of appearance and life satisfaction as a central issue of the psychological research in the field of appearance investigation. Basing on listed above theoretical concepts and empirical evidence the Multifactorial Model of Attitudes towards AP was developed. The value of $\mathrm{AP}$ and related to it functional significance of AP are placed into the center of the model. Demographic factors and individual's spheres of life are included in the model as determinant factors. The interplay of these factors influences not only the value of AP but also determine the attitude towards AP which contains selfestimations of $\mathrm{AP}$, concern and satisfaction with $\mathrm{AP}$, and appearance perfectionism. The interrelations between listed above factors, attitudes towards $\mathrm{AP}$, its value and functional significance determine in their turn life satisfaction, well-being, and level of social adaptation. The described interrelations influence the development of lookism and lookphobia relating to psychological and social-psychological difficulties in the spheres of business, interpersonal and intergroup communication (Figure 1). AIM AND HYPOTHESES OF THE STUDY

This study is aimed at empirical testing of the interrelations between factors described in the developed Multifactorial Model of Attitudes towards $\mathrm{AP}$ and at the defining of those factors that influence life satisfaction. Taking into account the peculiarities of the phenomena linked to AP as well as the results of our previous research we hypothesize that different combination of the single factors of the Multifactorial Model of Attitudes towards AP has different impact on life satisfaction.

PARTICIPANTS AND METHODS

The participants were 86 females and 86 males aged between 17 and 25 years ( $M=20.07, S D: 2.23)$. The modified version of the inventory "Diagnostics of Real Structure of Personality Value Orientations" developed by Bubnova S.S.
The questionnaire "Significance of

Appearance in Various Interaction Situations"

(Labunskaya V.A., Serikov G.V). was applied

to register significance of AP in different life

situation. Three questionnaires "Content-

Evaluative Interpretation of Appearance

"Attitudes towards Appearance: Satisfaction

and Concern"(Labunskaya V.A., Kapitanova

E.V.), and "Appearance Perfectionism Scale"

(APPS) (Srivastava K.) were applied to register the attitudes towards AP. Life satisfaction was measured using the Life Satisfaction Index (LSI) developed by Neugarten and adopted by N.V. Panina.

\section{Table 1. Descriptive statistics}

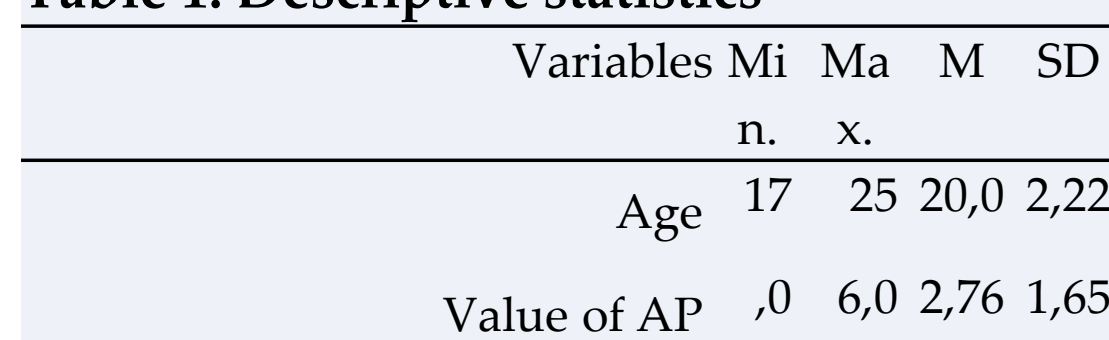

$\begin{array}{llllll}\text { Value of AP } \quad, 0 & 6,0 & 2,76 & 1,65\end{array}$

Self-estimation of face $1,0 \quad 10,05,94 \quad 1,83$

Self-estimation of body 1,0 10,0 5,29 2,20

Self-estimation of AP design 1,0 10,0 6,11 1,92

Self-estimation of AP sexuality 1,0 10,0 4,85 2,01

Self-estimation of AP for a $1,0 \quad 10,0 \quad 5,38 \quad 2,11$ partner of the opposite gender

Self-estimation of $1,0 \quad 10,0 \quad 6,18 \quad 2,06$ femininity/masculinity of AP

Integral self-estimation of AP 1,0 10,0 6,08 1,55 Concern with AP 2,2 9,6 5,15 1,58 Satisfaction with AP $\quad \begin{array}{lllll}1,0 & 9,8 & 6,19 & 1,84\end{array}$ Life Satisfaction Index (LSI) 4,0 39,0 20,3 8,18 Appearance perfectionism 1,2 7,0 3,95 1,56 Integral score of AP $1,0 \quad 5,0 \quad 2,74 \quad 1,05$ significance

\section{RESULTS}

$67.4 \%$ of participants have low level of LSI $23.3 \%$ reported middle level of LSI and only $9.3 \%$ of participants had high level of LS $(M=20.33$, Min=4.0, Max=39.0). Descriptive statistics (Table 1) showed that most of the participants $(50 \%)$ are agree with high value of $\mathrm{AP}$ and its important role in various life spheres. Self-estimation of the components and holistic characteristics of AP are associated with middle level of satisfaction and concern with $\mathrm{AP}$ and perfectionistic attitudes towards AP. At the same time the analysis of standard deviation revealed a large variation in attitudes towards AP.

The first factor (Table 2) includes all selfestimations of AP, satisfaction with $\mathrm{AP}$ and appearance perfectionism. Life satisfaction was also included in this factor with positive loading as well as concern with AP-with negative loading. According to psychological content this factor could be named "Attitudes towards AP-life satisfaction". The second factor contains value of $A P$, significance of AP in different life situations, concern with AP and appearance perfectionism. Life satisfaction has a negative loading within this factor. Referring to psychological content this factor could be named "Value and significance of AP - life dissatisfaction".

Altogether, higher life satisfaction is observed if higher attitudes towards AP (all components of self-estimation of AP: selfestimation of face, self-estimation of body, self-estimation of AP design, self-estimation of AP sexuality, self-estimation of AP for a partner of the opposite gender, selfestimation of femininity/masculinity of AP)are linked to satisfaction with $A P$, and appearance perfectionism while value of $A P$, significance of AP in different life situations, and concern with AP are significantly lower.
Lower level of life satisfaction is associated with higher value of $A P$, significance of $A P$ in different life situations, concern with $\mathrm{AP}$, and appearance perfectionism.

\section{Table 2.Varimax rotation matrix}

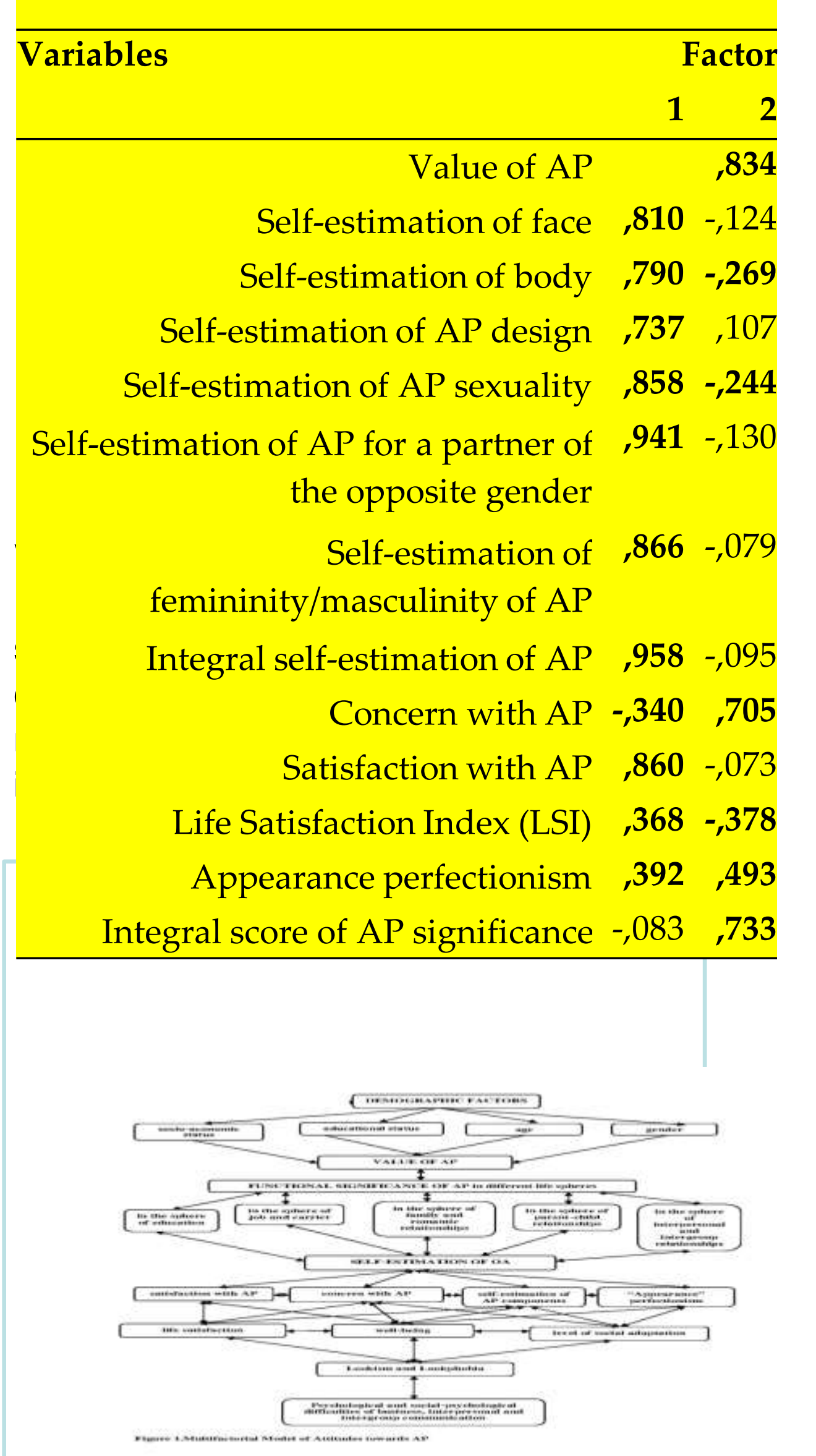

Copyright @ 2019 Labunskaya Vera vlab@aaanet.ru 